\title{
BEYOND RECORDS AND REPRESENTATIONS: INBETWEEN WRITING IN EDUCATIONAL ETHNOGRAPHY
}

\author{
Rebecca Coles and Pat Thomson \\ School of Education, The University of Nottingham, UK \\ Rebecca Coles \\ rebecles@gmail.com \\ Pat Thomson \\ patricia.thomson@nottingham.ac.uk
}

Rebecca Coles $\mathrm{PhD}$ is currently a research fellow working on a project tracking the involvement of young people in Circuit, a national youth-arts programme coordinated by Tate. Her PhD examined the learning that occurred in an independent art house cinema in an English Midlands city.

Pat Thomson PSM PhD is Professor of Education and Director of the Centre for Research in Arts, Creativity and Literacies in the School of Education, and Director of the Centre for Advanced Studies (faculties of Arts and Social Sciences), The University of Nottingham. Her current research includes a longitudinal study of teachers and students working with the Royal Shakespeare Company Education and Tate Learning, a longitudinal study of young people in Circuit, a national youth arts programme coordinated by Tate, and a long-term participatory ethnography of learning at Tate. Her most recent publication is Detox your writing: Strategies for doctoral researchers (with Barbara Kamler, 2016, Routledge). 


\title{
BEYOND RECORDS AND REPRESENTATIONS: INBETWEEN WRITING IN EDUCATIONAL ETHNOGRAPHY
}

\author{
Rebecca Coles and Pat Thomson \\ School of Education, The University of Nottingham
}

\begin{abstract}
:
Ethnographers are particularly interested in writing. They have paid particular attention to the practices of making field notes and to the ways in which their public texts represent those that they have encountered and studied. To date there has been less attention paid to the kinds of writing that is used to make sense of experiences in the field. We call this inbetween writing. By examining our own processes of inbetween writing, and drawing on the work of James Clifford, we have produced a nine-part heuristic of inbetween writing. We argue that the heuristic could be used in research methods education to highlight the importance of writing to ethnographic sense-making and knowledge production.
\end{abstract}

Key words: writing, ethnography, methodology, arts education 


\section{BEYOND RECORDS AND REPRESENTATIONS: INBETWEEN WRITING IN EDUCATIONAL ETHNOGRAPHY}

What does the ethnographer do? He (sic) writes.

(Geertz 1973, 19)

From the late nineteenth century onwards, ethnographers have been heading out into the world clutching their notebooks and pens. Their goal was to describe and understand social life in vivid detail.

Besides putting themselves in the shoes of the people whose ways of life they study, ethnographers work differently from most other researchers by virtue of other qualities of their research, such as its ability to portray people, places, and times in vividly descriptive detail, and its emphasis on the researcher's immediate and direct involvement with, participation in, and experience of the life-world object of study. (www.publicethnography.net)

While they might also carry a camera and/or a device for recording sound, the ethnographer's basic kit was something to write with and something to write on. Noone would be caught in the field without the means to write down their observations. At night, or perhaps some time later, notes taken in the field were turned into a description of the various people, places, events and conversations that had been encountered. Later still, usually back at home, the ethnographer read through all of their notes and subsequent writings, and then produced a more polished piece to communicate their experiences to a wider public.

The understanding that this kind of practice was, and is still, all there is to ethnographic research has been challenged. In this paper we signal some of this history, using it to locate our interest in inbetween writing. We begin our paper by explaining this interest and its origin.

\section{A focus on the inbetween}

Our shared interest in ethnographic writing sprang from a post $\mathrm{PhD}$-submission reflection. Becky's doctoral research was an ethnographic study of the educational practices of a regional independent cinema. This involved eighteen months of fieldwork, which included interviews and archival research combined with filling those ubiquitous notebooks with observations. As well as turning these notes into more coherent descriptions of each day, Becky also wrote other kinds of texts, texts which began to develop and extend her thinking about what she was seeing, hearing and doing.

When Becky (at the time a nearly Dr) and Pat (supervisor) were preparing for the viva, Pat suggested that examiners were likely to ask a question about analysis. Becky observed that she hadn't really used anything that looked like a conventional 'method' - there was no coding or thematising. Instead, she had written and written and read and then written more. Pat noted that she often worked like that in ethnographic research too. 
We started to think then and there about our shared process. We had both read David Mills and Missy Morton's (2013) discussion on 'the dual tradition' in educational ethnography and wondered if this was an explanation for our shared preference for writing as a key process in making sense of our 'data'. Mills and Morton identify one group of educational ethnographers who are aligned with an implicitly post positivist approach and another who see ethnography as more intuitive and experimental. The former, Mills and Morton suggest, advocate practices which approximate the dispassionate and systematic processes associated with science, such as coding and thematising; they explicate and teach that these are the "methods' that ethnographers must use. The latter by contrast, assume an interpretive position, understanding ethnography as a process of tacking back and forth between theoretical concepts and empirical materials. According to Mills and Morton, the latter group takes a holistic view of writing and analysis. Even though we didn't necessarily agree with the binary in the Mills and Morton argument, we did see that we seemed to fit in the second group.

With the notion of interpretation now firmly fixed in our minds, we decided to take our interest in writing further. Because we had at that point only come across a little in the ethnographic 'methods' literatures about writing as a sense-making process, we decided that, post-viva, we would investigate further. This paper is the result of that joint investigation. We began by examining the contents of this journal, Ethnography and Education, as well as conducting a more general search of educational ethnographic writing.

First of all we looked at a paper by Geoffrey Walford on field notes. Walford wasn't focused on teaching people the craft of note-making (as were for example Emerson, Fetz, and Shaw 1995), but sought to reveal the hidden practices of ethnographers. Rather than a personal revelation about his own note-making (e.g. Van Maanen 1988), Walford conducted interviews with practicing educational ethnographers. In the paper (Walford 2009b) he describes field notes as "the record from which every article and book about the ethnographic research draws and against which every ethnographer tests developing ideas and theories" (p. 117). The point of fieldnotes, he writes, is "to record as much as possible of what is perceived to be relevant to the research process" (p. 127). In a more general paper about ethnography in the next issue of the journal, Walford (2009a) argues that a desirable finished ethnographic text limits "distortion" and "multiple meaning" and is clear about what empirical claims it makes (p.279). The role for writing is summed up in the injunction Walford quotes from Paul Willis (2000):

Write down what happens, take notes about what people do and say, how they use objects, artefacts and symbolic forms in situ. [...] Tell me something - I know all the method problems - tell me, tell your readers, something about the world" (p. 280).

We noted that, in Walford's papers, the writing that takes place between the field notes in paper one and the completed text in paper two, the writing with which we were concerned, was not discussed. Nor is it in Willis' oringal text. We do not assume that this absence is because this inbetween writing did not occur, nor that these authors were uninterested in this process, but rather that discussion in the field has to date not seriously considered the inbetween in detail. 
We also saw in this journal considerably more interest in crafting the final ethnographic text - how the work of ethnography is made public. A special issue of the journal, Volume 4, number 3, edited by Carl Bagley and entitled Shifting boundaries in ethnographic methodology, featured nine papers which variously discussed arts-based, digital and performance turns in ethnography. Bringing social science and arts together to transcend the lingering traces of post-positivism, this special issue canvassed new processes of textual construction in which writing in different genres and media expands the capacity to communicate meaning. (Walford's second paper is from this issue of the journal and does challenge some of the arguments made by other contributors.) However, we noted that the process of getting from the fieldnotes to this final arts-informed text did not feature in these special issue discussions.

On the basis of the silence around inbewteen writing in the major journal on educational ethnography, we decided that some discussion of the notion and practice of inbetween ethnographic writing would perhaps be useful. This paper thus aims to contribute to raising the profile of the writing work that happens between records and representations. Our hope for this paper is that is a conversation starter.

To continue our thinking we next went back to some of the wider literatures about ethnography and writing.

\section{Writing and ethnographic practice}

Early anthropological ethnographers understood that they were conducting a scientific inquiry. However, rather than seeking generalisable laws, they attempted to trace the contemporary histories of diverse human societies, demonstrating the veracity of their 'findings' through the collection of evidence accrued through deep immersion in their chosen site. While this was undoubtedly a process which required interpretation, and while the societies they studied were changing even as they were being studied, ethnographers did view what they did as finding 'truths' (Eriksen and Nielsen 2001). However, within the different anthropological disciplinary traditions there was a shared recognition that the ethnographer was the vehicle through which truthful interpretations were produced (Barth et al. 2005).

By the mid twentieth century, the notion of truth, as well as the mission of ethnography, was under serious duress. Anthropologists had long been uncomfortable about the connections between their research and the colonial activities of various nation-states and the ways in which mediating institutions, such as museums, categorised and displayed anthropological 'findings' (Bennett 2013). The practices of representation - the ways in which 'other' societies were understood - came in for particularly stringent critique. As Renato Rosaldo puts it,

Once upon a time the Lone Ethnographer rode off into the sunset in search of "his native". After undergoing a series of trials, he encountered the object of his quest in a distant land. There he underwent his rite of passage by enduring the ultimate ordeal of "fieldwork". After collecting "the data", the Lone Ethnographer returned home and wrote a "true" account of "the culture" (Rosaldo 1989, 30) 
Rosaldo's satirical words signal the problematisation of past anthropological practices - they were a romantic and deluded quest bound to produce an inaccurate set of results.

Anthropologists were 'early adopters' of the 'linguistic turn' (e.g. Rorty 1967, Wittgenstein 1976), in which, influenced by a range of linguistic, philosophical and historical writings, both social scientists and humanities scholars adopted a set of understandings about knowledge in which language was heavily implicated (Barnard 2000). Rather than understanding the practice of research, and ethnography in particular, as being an objective process of finding 'truth', scholars held that:

- words are not a transparent window on the world

- writing is work with languages that are specific to particular cultures, times, spaces and places

- because writing is not a simple mimetic process of recording an external 'truth', scholars engaged in translating from one culture and language to another run the risk of grossly misapprehending what they see and what they are told

- the practices of research, including ethnography and its writing, are framed by the researcher's own social, racial and gendered positioning

- language use, whether spoken or written, is a sense-making practice, and

- authoring a text is also simultaneously authoring an interpretation of the world (Geertz 1988, Clifford and Marcus 1986, Behar and Gordon 1995).

Ethnographers have grown increasingly interested in the writing process (for example see https://www.dur.ac.uk/writingacrossboundaries/), the potential for conflict between ethnographers and the subjects of their study (Brettell 1996), and the opportunities to use multiple genres, artistic forms and multi-media to communicate interpretations (Richardson 1997).

These were the literatures with which authors in Ethnography and Education would have been familiar and which underpinned the special issue on performative texts.

\section{Literatures relevant to inbetween writing}

As we widened our search to see what was written about the processes of writing in (educational) ethnography we saw scholarship primarily directed to the need to focus on writing, making fieldnotes and producing final texts (e.g. Atkinson and Delamont 2008, Noblit, Flores, and Murillo 2004). We did find some concerns with inbetween work. While not directly addressing our particular topic, Wolcott's overall focus - on ethnography as an artistic creative process (Wolcott 1995), and on the crucial and ongoing role of writing in qualitative research (Wolcott 2001) - resonates strongly with us.

We also read an essay by Bob Jeffrey (1999) exploring "early" ethnographic writing memos, vignettes and letters to supervisors - in which the analytic and creative work of ethnography tales place. It is the critical climate which this range of texts produces, Jeffrey argues, which allows the object of research to be distanced. Such writing has three roles: it encourages the ethnographer to identify with, and to immerse $\mathrm{him} /$ herself in, the lives of others and to overcome prior assumptions about them; it 
stimulates metaphors and allows the ethnographer to play at presenting the world in different ways on a journey to discern the most appropriate; and it engages comparative contexts, which stimulate conceptualisations and analytical insights.

Jeffrey's essay can be read as describing the inter-textual process of producing ethnography. It is a process in which many different texts - different accounts and observations about the site, the thoughts of other academics, and those tied to "personal enthusiasms" - are bought into conversation. It is a process in which different attempts at writing - some more focused on empirical description and some more on the development of more abstract theory - are either abandoned or developed to become part of one finished text. Here was a commonality with our view that inbetween writing was an important process of making meaning of initial field notes.

As we read, we located some ethnographers who have turned away from questions of representation and towards notions of knowledge production. Important for our concerns are:

- Rabinow, who argues that the processes of anthropological knowledge production and the ways in which categories of knowledge are brought into being need to be subject to critical scrutiny, rather than taken for granted (Rabinow 2007, 2011). This is a concern shared by the anthropologist Ingold (2011), who has written extensively about ways of knowing, and by some sociologists (e.g. Back and Puwar 2013, Lury and Wakeford 2012) who argue the need to examine the 'liveness' of methods, to focus on what actually happens in the field beyond making notes. This line of argument supports an investigation of inbetween writing as knowledge production.

- St Pierre, Tanggaard and colleagues who argue that research is a process of searching for associations and traces through thinking and thinking-writing, rather than the technical application of 'methods' (e.g. St Pierre 2011, Tanggaard 2013). This argument supports an investigation of inbewteen writing as a thinking practice.

- Pink, who argues that the importance of the ethnographer's subjectivity is crucial. As she puts it,
Ethnography is a process of creating and representing knowledge (about society, culture and individuals) that is based on the ethnographers' own experiences. It does not aim to produce an objective or truthful account of reality, but should aim to offer versions of the ethnographer's experiences of reality that are as loyal as possible to the context, negotiations and inter- subjectivities through which the knowledge was produced. (Pink 2009, 8)

This does not mean a narcissistic obsession with the self, nor that the research produced is somehow 'authentic'. Rather we understand Pink to mean that the researcher's subjectivity needs to be recognised and reflexively taken account of in the production of, as well as in the final ethnographic text. We were thus encouraged to look further at our own inbetween writing practices.

These writers affirmed our view that examining the ways in which ethnographers make meanings is both worthwhile and important. They drew our attention to the sometimes inchoate ways in which associations and inferences arise during what is known as 'inductive" research in the more traditional methods literatures. They also 
supported our view that thinking about our own uses of writing as a way of producing knowledge could be beneficial.

We also found further writing relevant to inbetween work in the broader qualitative research literatures. A special issue of the journal International Journal of Qualitative Studies in Education (2013, 26, (6)) entitled "Post-qualitative research" interrogates and deconstructs the reality/representation binary and the very notion of 'data', and pursues the ways in which researchers might move, through writing-thinking, to different kinds of research practices. And a special issue of Qualitative Inquiry (2014, 20 (6) entitled "Qualitative data analysis after coding" further amplifies concerns relevant to inbetween work. Authors in this issue proceed on the understanding that qualitative research is about astonishment, mystery, and breakdowns in understanding. The researcher can then ask "How is it possible? What discourses, relationships, and theories of self and subjectivity must be obtained for this material, this instance, to make sense?" (Brinkman 2014, 723).

In this Qualitative Inquiry special issue it is Sharon Augustine (2014) who describes her writing process most explicitly. For her, interviewing, writing memos, transcribing interviews, and writing interpretation all happen at once. Writing is "a machining or putting together of participants' reading experiences with theoretical concepts" (p. 750). As theories and the words of participants are squeezed into language, she writes, new connections among ideas occur. Writing makes it possible to see in data something other than what the researcher went looking for, something that can be bought to the limits of thought. This is very resonant with our own inbetween writing practice.

We take from this body of work that we are not alone in arguing for thinking/writing as a way of understanding, as a mode of analysis. And while we do not step into the 'beyond representation' arguments in this paper, we can see that it has congruence with our understanding that inbetweeness is about more than putting something already known into a particular kind of text. Writing as thinking, and rewriting as continuing to think, are ideas similar to our own, as we will show.

Finally, we found writing from James Clifford relevant to our concerns with analysing our own inbetween writing. Clifford (1990) argues that there are three moves in ethnographic writing:

- "inscription" when a phrase or observation is jotted down in order that it is remembered;

- "transcription" when already formulated discourse is transcribed;

- "description" when a coherent representation of an observed cultural reality is written.

While these moves can be accomplished as discrete writing tasks, they are often blended, or they alternate, in ethnographic writing.

Clifford reasons that none of this writing can be seen as 'original' in that it all refers to other texts. Inscription involves the ethnographer noticing a fact and finding it important, an act which presupposes some prior framework, some conceptual topography - understood in and as language and text - to which it belongs. The 
process of transcription necessitates making an interpretation of a text that already exists - either as recorded or noted speech for example - and re-reading and rewriting it. The transcription is a version of an a priori text which is already different from the material events it records. And in description, Clifford suggests, the ethnographer smooths out tensions and inconsistencies in their account, producing something which appears seamless and coherent. The ethnographer's writing produces an appearance of a unitary and wholistic view, erasing other possible and existing texts, discourses, gaps and perspectives.

Clifford argues that writing is always, to some degree, both inter-tetxual and a process of rewriting. His aim was to make visible the systems - contextual, rhetorical, institutional, generic and political - which determine ethnographic knowledge (c.f. Clifford and Marcus 1986). Clifford posits a meaning-making process in which a spectrum of interrelated polyphony is at play - this includes what is in conflict within the oral and transitive reality being observed, and what is in conflict between this reality and prior ethnographic texts and theory. He also proposes a process of rewriting what the ethnographer has herself written: description is a sustained period of engagement with the process of creating one coherent representation. Clifford's threepart typology of different kinds of ethnographic inter-textuality is one way of thinking about the processes of the production of knowledge in ethnographic research.

We have worked with Clifford's insights in order to consider our own inbetween writings.

\section{Inbetween writing in and as practice}

We now turn to our inbetween writing practices. We give three examples, each of which blends several kinds of writing but which have different concerns: the first deals with writing that brings together different descriptions, the next deals with writing that brings together description and an emerging analytic framework; and the last deals with writing that brings together description and other texts. Our purpose is both to illustrate the interest in 'early writing' and creative thinking that Jeffrey discusses, as well as the kinds of 'inter-textuality' that Clifford argues are critical to the processes of knowledge production.

\section{Example One: writing descriptions with other descriptions in mind}

This first example is taken directly from Becky's $\mathrm{PhD}$ thesis. The research was conducted in a place of non-formal education - a cinema of the 'arthouse-multiplex' kind (Tudor 2005). The cinema is a place where many different educational activities co-existed: events to support the creative industries, filmmaking with young people, evening courses and introductions to films. The task of making sense of such a diversity of activity initially seemed overwhelming. What dimensions could be used to compare and contrast them? What meaningful summary could be generated? These questions were approached through the process of writing sets of descriptions in parallel. The purpose of the dual texts was to produce rich descriptions, but also to write each description with the other description in mind.

Below we show a pair of Becky's texts which describe two different 'Q\&A' events these texts were developed together: 


\section{Description One}

In December the director Terrance Davies visits to talk at a screening of his new film (an adaption of Rattigan's 'The Deep Blue Sea'). It is sold-out. As the film ends, the lights come up and there is applause as Davies is introduced. He sits at the front of the cinema across from an interviewer. She begins to ask questions and then later selects audience members to ask them. His answers develop into expansive personal narratives with which he controls the direction of the discussion and its mood which comes to reflect the use of time, place and emotion in the film.

Memory is emotional, cyclical not linear, he says. So it's an interesting way of telling a tired story: if a character is in a state of semi consciousness, you can go anywhere. Rattigan never lived in a bed sit in the 50's; he never experienced the cold, the quiet, the rent needing to be paid, cheap furniture, a shared toilet, one gas ring. "It was very shabby...There was no primary colour... I remember my aunt's huge ebony sideboard with a mirror... I don't know how they go it in... The houses were tiny... There was no credit, or you had to pay it back very quickly... Things were very well kept but shabby... But there were still moments of magic."

He returns several times to describing evocatively his own memories. He speaks of a memory of potato cakes and tea and the smell of lavender floor polish. His pace of talking slows and his tone becomes increasingly charged. I hear audience members grunt in recognition.

\section{Description Two}

On Tuesday 10th January, the cinema hosts their first 'Live by Satellite' $Q \& A$, as part of a preview screening of Steve McQueen's 'Shame'. As the audience comes into the cinema, live film of another audience arriving - in Mayfair - is projected on the cinema screen. The picture roams around the other cinema showing the people there and focuses particularly on the few celebrities who enter, find a seat, and sit down. As the film projection ends, the live feed is again broadcast and the $Q \& A$ is shown, much like a TV chat show: the picture switches between framing-shots, mid-shots and close-ups of the interviewer and the film's writer and director who ignore the camera throughout and occasionally cuts to the London audience, particularly as they ask questions.

The regional audience of which I am a part is in a playful mood. As the host introduces the event, he lists some of the places where the event is being broadcast: "Birmingham, Manchester, Ipswich..." I mock shout in a whisper to my companion the name of the city we are in. The rest of the audience has the same idea and makes an "aaah" of regret together as he doesn't mention us. " $80 \%$ of internet traffic is pornography" McQueen states at one point. I and my companion exchange skeptical looks. As we do this we hear the audience in our cinema laughing. Turning back to the screen we see what they have seen. The audience in Mayfair also turn to each other in disbelief. We laugh then with our audience at the complex network of actions and responses, of performances, that the event is producing.

Writing these two descriptions together, and with each other in mind, allowed Becky to work creatively, making associations as she wrote, thinking about the one event, and then thinking about the other. As she worked on one text, knowledge about the other was also in her mind. She used field notes taken shortly after each event in order to prompt her memory and to ensure that she described what had seemed to be the most salient points, events and conversation at the time. Both descriptions are a rewriting of the initial events, but both are also an analytic move which prompted 
some thinking about key points of comparison across 'events'. This was not a formal process of coding, although some of the same thinking processes occurred - a search for the things that seemed to be most important.

Through these two descriptions written together Becky noted that the concept of "performance" might be helpful in thinking about different kinds of 'live' events held in the art cinema. This was a notion she later developed through reading and through further writing work around these and other events. She also saw some points of difference between the two events which she thought were significant. While in the live Q\&A, performance was reserved for the Director, at the Live by Satellite version, it fractured and multiplied. The frisson of being in the same room as the filmmaker, the tension of being an audience to his performance, was absent. Instead, the audience played with their relation to other individuals physically present with and audiences participating across the country. This was an insight which she developed much further as the thinking-writing went on.

Becky worked iteratively across various events that she had recorded in her field notes. As not only pairs, but also larger constellations, of descriptions were developed, each description drew out the dimensions of the others. Many of the points and pieces of text were eventually incorporated into the final thesis.

\section{Example Two: writing descriptions with a larger analysis in mind}

We turn now to a small chunk of writing that began this paper. An early and larger version of this text was first written for the methodology chapter in Becky's thesis. During the development of this paper it was re-written and tightened up many times. The purpose was to try to work from the description to an analysis. This writing illustrates not only the production of a description but also the ways in which fieldnotes and memories work together, they continue to be formed, they are being written and re-written.

I begin by jotting down fieldnotes in situ. Then, within a few days, I use them to produce chunks of descriptive writing. I then continue to write and re-write these descriptions, inspired to amend, edit or expand them by putting them together in different combinations and adding into their midst reflections on existent theory. In this way I develop longer and more complete accounts which more clearly draw out the relevant dimensions of what I gradually find I want to describe. I use writing as a way to make sense of my data, to get ideas and themes to emerge, to generate categories and frameworks and to produce summarisable findings. This writing is a process of meaning-making.

This text is working towards an analysis. Key activities are identified - initial writing, the ways in which field notes and theory both appear, the process of understanding as it emerges.

As Becky wrote and rewrote this single paragraph she honed ideas about what exactly was important. Through this tiny text, through trying to pin down more and more precisely what mattered, and experimenting with different ways of categorising and labeling, she arrived at a point where the text could be brought into conversation with the readings that we had done. A series of themes emerged which were tested against 
this rewriting, as well as the extant literatures. The repeated re-crafting of this text was the central place of thinking that produced the fundamental argument of this paper. We show the final results of this analytic process (see Table 1) at the end of this section of the paper.

\section{Example Three: writing descriptions with other texts in mind}

Finally, we turn to one of Pat's working texts which describes an event at a Summer School for teachers held at Tate Modern in July 2014. The aim of the writing was to develop both a description from field notes, but also inform, through the process of writing, some of the thinking that she had been doing about the pedagogical processes involved. The writing was to be read by her research partners in the Tate Schools and Teachers team. The writing involves a description and writing a description with both other texts and a larger analysis in mind. The writing also begins to situate an analysis in relation to other texts.

The first activity on the first morning is to leave the Clore Learning Studio and to go out into the gallery. We not only don't know each other, we also don't know the Clore and now we are heading out into public. But there's a further catch. We are to work in pairs and one of us is to wear a hood. The hood is a Napoleon style cockade, but it covers the whole face - the wearer cannot see a thing. The cockade-hood is made of newspaper but the outside has been covered in a bright and very thick plastic paint. The non-hooded partner has to guide their unseeing and vulnerable dependent up two flights of escalators and then through the Meschac Gaba exhibition, all nine rooms of it, and explain what they see in sufficient detail for the 'blind' partner to imagine something the same.

It is an unnerving experience. I hang back and wait until one of the artists sees me lurking and firmly takes my arm, putting the cockade-hood on her own head. I now have to get her up and around the exhibition. I am highly conscious of making sure she doesn't trip and also of the need to provide enough information for her to 'see' what I do. The process is not helped by the fact that the paint used to cover the hoods is very smelly and it makes my partner feel very nauseous. I not only have to do the task of guiding and describing, but also make sure that she doesn't vomit.

I can't help but think simultaneously about trust walks and the impossibility of the task. How much description is enough, I wonder, to help someone 'see' the exhibition as I do (the irony of this worry for an ethnographer!). I am aware that I am noticing a lot more about the exhibition that I would do normally, in order to describe it to her. I wonder and then say aloud "What do people need to know in order to imagine something that is there?"

This event is, I also understand at the time and further on reflection, an activity which demonstrates some pedagogical processes -

(1) one of each pair is literally unknowing about what is happening and will happen - one object of contemporary art pedagogy is to support states of unknowing rather than knowing (Jones 2013)

(2) the experience requires some kind of instant curatorial explanation exemplifying the sheer impossibility of translating a visual experience into a verbal, as well as the incommensurabiity and arbitrary nature of 
interpretation. It also raises questions about whether two people can see and understand the same things when looking at an art object

(3) the activity relies on taking people out of their comfort zone - a contrast to the usual idea that the learner has to feel safe in order to take risks.

A further contemporary art trope - restricting freedom, in this case sight, in order to produce creative responses - is also in play.

There is some mileage in thinking about the role of the hood in this event. The learning on offer was made possible by the very specific use of the hood/object-I'm thinking Bennett (2010) on the power of the material. The hood focused us on the question of seeing and interpreting for another in a way that was both immediate and powerful. I do wonder if the kinds of learning that people did during the week was related to this first object-stimulated experience and if so how? This might be a good example of the object as part of the learning assemblage.

This text was first composed by bringing together field notes, memories, and some pieces of pre-existing writing and extant theory. It was first written at home a couple of weeks after the event and then rewritten a year later as an inclusion in a larger set of reflections about key moments in Summer Schools. The purpose of this latter writing-reflection was to refine shared thinking about gallery education pedagogy. It was also to stimulate a developing conversation about the role of objects in learning in the gallery.

\section{An emerging heuristic of inbetween writing}

We have worked further with our writings to develop a heuristic that might be helpful in thinking about the various forms and purposes of ethnographic sense-making. Our examples distinguished three modes of ethnographic writing: (1) writing groups of descriptions in order to explore and produce their meaning; (2) writing analytically oriented description in order to think abstractly; and (3) writing reflections which put developing analysis in direct conversation with other literature and analysis. These were and are most fundamental to our own thinking-writing processes.

We have used these three modes as the foundation of our heuristic which describes the different processes of inbetweeen writings and the different kinds of texts that are produced (see Table 1). The two key axes that we use are those of rewriting, and of intertextuality, the two we derived from Clifford's (1990) work, as explained earlier. We placed the three modes of writing along these two axes, and drew further from the literatures and from our own writings, and came to 'see' three moves of intertextuality - writing between memory, notes, transcripts and collected materials, writing between different descriptions, and writing between descriptions and other literature - and three moves of rewriting - description, re-description and reflection. When these are all combined, they produce a grid of nine different 'moves' that occur in inbetween writing.

Table 1: A heuristic for inbetween ethnographic writing

We suspect that there might be some benefit in thinking about these moves separately. However, we know from our own writing that we often combine several of them together. Although our Example Two, for example, was used to exemplify inbetween 
writing of descriptions with a larger analysis in mind, it also exemplifies inbetween writing, articulating the process through which fieldnotes and memories were and continue to be formed. Also, although many of the moves themselves involve an iterative process, inbetween writing often also iterates between moves. To return again to our Example Two, it is an artifact of a process which moved between rewriting a description by checking it against notes and transcripts and writing a description with a larger analysis in mind. We are describing different writing processes as well as different kinds of text.

Our writing examples may thus seem to be entirely unremarkable, the kinds of texts produced by many ethnographers. They are, and that is our point. Our hunch is that many ethnographers engage in the process of inbetween writing, but it is something that we take for granted, or see in terms of finished texts. Inbetween writing is thus a familiar we hope to make a little strange.

Like others interested in writing as an integral part of academic practice we believe that writing is a craft which must be practiced. We join with the anthropologist Kirin Narayan (2012) who argues for writing as an everyday habit. Her own habits of writing suggest that writing can/should be something that ethnographers routinely undertake as a way of reflecting, developing ideas, interrogating taken for granted narratives and concepts. St Pierre and Jackson have argued along similar lines. They advise students that analysis requires writing/thinking. Analysis is not, they suggest, a stage, but rather a continuing process that is "emergent and experimental" and its "space-time cannot be secured in the traditional linear "process" trajectory of data collection>analysis $>$ representation" (St Pierre and Jackson 2014, 717). This chimes with our view.

Like St Pierre and Jackson our interest, being educators, is on the potential pedagogies that might emerge from thinking about thinking-writing. We are concerned to develop a pedagogical approach which not only supports a writing habit but also an habituated way of thinking and reasoning that happens through the writing. Like St Pierre and Jackson, we think that this is not simply about knowing and doing but it is something that is ontological, about a way of being and doing research.

We know that there is an interest in bringing questions of writing to the fore in teaching about research practice (Kamler and Thomson 2006/2014). And we know that many who teach ethnographic methods do encourage students to practice writing descriptions. They sometimes send students out into public areas and ask them to note what they see and then bring that writing back to class for a critical discussion about crafting a richly descriptive text (1). We do this ourselves too. However, we note here Clifford's (1990) argument that ethnographers have paid too much attention to description when thinking about writing.

Ethnography cannot in practice maintain a constant descriptive relationship to cultural phenomena. It can maintain such a relationship only in relation to field notes... One form of ethnographic writing, description, has too often been made to stand for the whole ethnographic process. (p.68) 
Clifford's warning lends support to the notion that learning to work with a range of writing practices and text types might be of value, and that pedagogical approaches to support a diversity of thinking-writing might be helpful.

We propose that our nine-part inbetween writing heuristic lends itself to the development of formal writing 'exercises'. This is of course a next step, one beyond the scope of this paper. We do however note that Bud Goodall's (2000) work provides an example of how this pedagogical work might be realised. Writing the new ethnography offers exercises for working from field notes, and authoring well crafted 'new ethnographic' texts. We can see the same exercise-focused possibilities in relation to inbetween writing. Those new to ethnography practices might, for example, not only learn how to make field notes in their methods classes, but also engage with the nine 'moves' that we have identified in order to see - through the writing and reflecting on that writing - what each of them accomplishes.

\section{In sum}

We suggested at the beginning of this paper that we had been unable to find, in either the ethnographic methods literatures or in scholarship about ethnography as a practice, a great deal about inbetween writing. While there was attention paid to field notes, and more to questions of representation, there was much less about the other writing that ethnographers do in order to make sense of their data. We saw however a growing interest in the processes of ethnographic knowledge production.

Ethnographers in both anthropology and sociology were particularly concerned with examining their own practices of producing culture, and not simply studying cultures in a range of local and global sites. Educational qualitative researchers were also interested in the practices of knowledge production, although this was not specifically tied to ethnographic traditions.

We see this paper as a small contribution to this growing interest in the cultures of ethnographers and their knowledge producing practices. However, we also hope that we have offered something towards thinking about pedagogies for ethnographic writing.

And we are interested of course, in developing the notion of inbetween writing further. We are conscious that the heuristic only reflects our own writing practices, and that there are likely to be both variations on our writing moves and others. We therefore hope the conversation about inbetween-ness continues.

\section{Notes}

(1) For example see http://www.mhhe.com/socscience/english/tc/blummalleyhawkins/blumANDhawkins module.html and http://www.asha.org/Publications/leader/2003/030318/030318b.htm.

\section{References}

Atkinson, Paul, and Sara Delamont. 2008. Representing ethnography. Reading, writing and rhetoric in qualitative research. Los Angeles: Sage.

Augustine, Sharon. 2014. "Living in a post-coding world: analysis as assemblage." Qualitative Inquiry 20 (6):747-753. 
Back, Les, and Nimal Puwar. 2013. Live methods. London: John Wiley \& Sons. Barnard, Alan. 2000. History and theory in anthropology. Cambridge: Cambridge University Press.

Barth, Fredrik, Andre Gingrich, Robert Parkin, and Sydel Silberman. 2005. One discipline four ways: British, German, French and American anthropology. Chicago: The University of Chicago Press.

Behar, Ruth, and Deborah Gordon, eds. 1995. Women Writing Culture. Berkeley, Los Angeles, London: University of California Press.

Bennett, Jane. 2010. Vibrant matter. A political ecology of things. Princeton NJ: Princeton Unviersity Press.

Bennett, Tony. 2013. Making culture, changing society. London: Routledge.

Brettell, Caroline B, ed. 1996. When they read what we write. The politics of ethnography. New York: Praeger.

Brinkman, Svend. 2014. "Doing without data." Qualitative Inquiry 20 (6):720-725.

Clifford, James. 1990. "Notes on (field) notes." In Fieldnotes. The making of anthropology., edited by R Sanjek. Washington DC: Cornell University Press.

Clifford, James, and George Marcus. 1986. Writing culture: The politics and poetics of ethnography. Los Angeles: University of California Press.

Emerson, Robert, Rachel Fetz, and Linda Shaw. 1995. Writing ethnographic fieldnotes. Chicago: University of Chicago Press.

Eriksen, Thomas Hylland, and Finn Sivert Nielsen. 2001. A history of anthropology. London: Pluto Press.

Geertz, Clifford. 1973. The interpretation of cultures. New York: Basic Books.

Geertz, Clifford. 1988. Works and lives. The anthropologist as author. $1994 \mathrm{ed}$. Stanford, California: Stanford University Press.

Goodall, H. 2000. Writing the new ethnography. Walnut Creek, Lanham \& New York: Alta Mira Press.

Ingold, Tim. 2011. Being alive. Essays on movement, knowledge and description. London: Routledge.

Jeffrey, Bob. 1999. "Distancing research objects through involvement of the self." In Studies in educataional ethnography edited by A Massey and Geoffrey Walford, 163-182. New York: Jai Press.

Jones, Rachel. 2013. "On the value of now knowing. Wonder, beginning again and letting be." In On not knowing. How artists think, edited by Elizabeth Fisher and Rebecca Fortnum. London: Black Dog Publishing.

Kamler, Barbara, and Pat Thomson. 2006/2014. Helping doctoral students write: Pedagogies for supervision. London: Routledge.

Lury, Celia, and Nina Wakeford. 2012. Inventive methods.The happening of the social. London: Routledge.

Mills, David, and MIssy Morton. 2013. Ethnography in education. London Sage.

Narayan, Kirin. 2012. Alive in the writing. Crafting ethnography in the company of Chekov. Chicago: The University of Chicago Press.

Noblit, George, S Flores, and E Murillo. 2004. Postcritical ethnography: An introduction. Cresskill, NJ: Hampton Press.

Pink, Sarah. 2009. Doing sensory ethnography. Thousand Oaks: Sage.

Rabinow, Paul. 2007. Making time: On the anthropology of the contemporary. Princeton, NJ: Princeton University Press.

Rabinow, Paul. 2011. The accompaniment: Assembling the contemporary. Chicago: The University of Chicago Press. 
Richardson, Laurel. 1997. Fields of play. Constructing an academic life. New Brunswick, NJ: Rutgers University Press.

Rorty, Richard, ed. 1967. The linguistic turn: Recent essays in philosophical method. Chicago: The University of Chicago Press.

Rosaldo, Renato. 1989. Culture and truth. The remaking of social analysis. $1993 \mathrm{ed}$. Beacon Press: Boston.

St Pierre, Elizabeth. 2011. "Post qualitative research: The critique and the coming after." In The Sage handbook of qualitative research, edited by Norman Denzin and Yvonna Lincoln. Los Angeles: Sage.

St Pierre, Elizabeth, and Alicia Youngblood Jackson. 2014. "Qualitative data anslysis afetr coding." Qualitative Inquiry 20 (6):715-719.

Tanggaard, Lene. 2013. "Troubling methods in qualitative inquiry and beyond." Europe's Journal of Psychology 9

(3):http://ejop.psychopen.eu/article/view/647/html - r15.

Tudor, A. 2005. " The rise and fall of the art(house) movie." In The sociology of art: ways of seeing, edited by D Inglis and J Hughson, 125-138. Basingstoke: Macmillan.

Van Maanen, John. 1988. Tales of the field. On writing ethnography. Chicago: The Unviersity of Chicago Press.

Walford, Geoffrey. 2009a. "For ethnography?" Ethnography and Education 4 (3):273-284.

Walford, Geoffrey. 2009b. "The practice of writing ethnographic fieldnotes." Ethnography and Education 4 (2):117-130.

Willis, Paul. 2000. The ethnographic imagination. Cambridge: Polity Press.

Wittgenstein, Ludwig. 1976. Philosophical investigations. Translated by G E M Anscombe. Oxford: Basil Blackwell.

Wolcott, Harry. 1995. The art of fieldwork. Walnut Creek, CA, London \& New Delhi: Alta Mira Press.

Wolcott, Harry. 2001. Writing up qualitative research. 2nd ed. Thousand Oaks, London \& New Delhi: Sage. 